\title{
La instrumentalización pública del patriotismo: una controversia intelectual en México (1703)
}

\section{The Public Instrumentalization of Patriotism: An Intellectual Controversy in Mexico (1703)}

\author{
Trilce Laske \\ Université de Toulouse, Francia \\ (D) orcid.org/0000-0003-0717-8410 \\ laske.rosas@gmail.com
}

Resumen: Este artículo trata de una polémica intelectual ocurrida en México en el año de 1703. Provocada por los discursos de superioridad académica del nuevo arcediano vasco, la controversia se vio rápidamente recuperada por un importante partido de la capital, que desplazó la controversia hacia la cuestión patriótica. Historiográficamente, este artículo sigue y pretende contribuir a una corriente reciente, que cuestiona la dimensión efectiva del criollismo en Nueva España. En el caso de la polémica y a inicios del siglo, el patriotismo surge como una herramienta meramente instrumental en manos de una elite que, con base en imputaciones cuestionables, lo usa como resorte político para movilizar el espacio público.

Palabras clave: intelectuales; criollismo; espacio público; Nueva España; elites.

Abstract: This article addresses an intellectual controversy that took place in Mexico in 1703 . Triggered by the statements of academic superiority by the new Basque archdeacon, this issue was rapidly taken up by a significant section of the city, which shifted it towards patriotism. Historically, this article follows and seeks to contribute to a new current that questions the effective dimension of criollismo in New Spain. As regards the controversy, in the early 18th century, patriotism emerged as a purely instrumental tool in the hands 
of an elite which, on the basis of dubious allegations, used it as a political tool to mobilize the public space.

Key words: intellectuals; criollismo; public space; New Spain; elites.

Fecha de recepción: 4 de enero de 2017 Fecha de aceptación: 5 de abril de 2017

\section{INTRODUCCIÓN: TEMA Y PROBLEMÁTICA}

$\mathrm{L}$ a mañana del jueves 16 de agosto de 1703, la capital de Nueva España amaneció con efervescencia. Durante la noche, varias copias de un mismo pasquín satírico dirigido en contra del arcediano del arzobispado fueron pegados en diferentes partes de la ciudad (Robles, 1972, t. III, p. 281). Encontrado incluso en uno de los pilares de la catedral, el pasquín ridiculizaba el sermón de la Ascensión pronunciado por Suazo, el día anterior, en el púlpito de la primera iglesia de México, delante de la ciudad reunida por el culto. Aunque resonante, la operación nocturna sólo constituía el nuevo acontecimiento de una polémica intelectual, empezada ocho meses antes. Su problemática, inicialmente centrada sobre las jerarquías académicas en el imperio, desbordó rápidamente de las fronteras de la esfera erudita. En términos de actores, por una parte, la controversia incorporó precozmente, como instigadores o simples participantes, individuos situados fuera del ámbito letrado, sean altos funcionarios capitalinos o la virreina en persona. En términos de escenarios, por la otra, lejos de circunscribirse a los límites del campo intelectual, se desarrolló además en gran parte delante de un espacio urbano amplio y heterogéneo, aficionado a las disputas de todo tipo.

¿Cómo una polémica de orden específicamente erudita llegó a alcanzar tal magnitud? Como respuesta, este texto se propone poner en evidencia la recuperación de la controversia, y luego su instrumentalización, por parte de un poderoso pero debilitado partido de la capital, cuya finalidad era forjarse una legitimidad política nueva. De manera más amplia, se trata de interrogarse sobre un patriotismo urbano, retrospectivamente denominado criollismo, sus efectos y funciones en una de las primeras metrópolis americanas del imperio hispánico, a través de una metodología enriquecida tanto por el análisis de los paratextos editoriales como por el examen de las sociabilidades.

\section{()(1) $\$$}




\section{EL ARRANQUE DE LA POLÉMICA: LA INTEGRACIÓN DE UN ALTO FUNCIONARIO PENINSULAR}

La controversia se inició progresivamente a partir del verano de 1702 con la llegada a México, el 23 de junio, procedente de la península, del nuevo arcediano (Robles, 1972, t. III, p. 233). La dignidad, segundo cargo del Cabildo catedralicio, se encontraba vacante desde el sábado 20 de octubre de 1698 debido al repentino fallecimiento de José de Adame y Arriaga, quien la estuvo asumiendo unos ocho años. Dependiendo del patronazgo real como el conjunto de las prebendas eclesiásticas en tierras americanas, el Consejo de Indias la atribuyó en junio de 1701 a Diego Suazo y Coscojales. El eclesiástico, residente de Castilla pero originario de Vizcaya, entró oficialmente en funciones el miércoles 5 de julio, quince días después de su llegada, con la desventaja de ser un alto funcionario externo, impuesto por la corona desde la corte madrileña. Entre otras dificultades, esta condición suponía un doble obstáculo inicial a su integración tanto institucional como social.

A nivel de la institución arzobispal, el nuevo dignitario tenía que lidiar con la reserva o reticencia del grupo clerical en general y con el descontento de su alto clero en particular, primer afectado por el nombramiento del vasco. Primero, Suazo y Coscojales acaparaba un puesto que los dignitarios de la arquidiócesis estimaban como suyo en su progresión hacia los más eminentes cargos. Segundo, el recién llegado poseía una hoja de servicio bien modesta, que contrastaba negativamente con la envergadura profesional de la mayoría de los capitulares. Con unos 50 años, ${ }^{1}$ Suazo no tenía todavía ninguna práctica concreta del gobierno diocesano, ni tampoco de la administración del culto en general, fuera de diversos sermones, pronunciados para grandes celebraciones anuales. ${ }^{2}$ En cuanto a su trayectoria universitaria, si bien resultaba más notable, aparecía también pobre en relación con la mayoría de los precedentes arcedianos (véase cuadro 1).

Antiguo alumno del Colegio Mayor de San Ildefonso de Alcalá de Henares, el hombre de Madrid debía su promoción en realidad, y como muchos antes de él, más a su origen académico que a su propia carrera (Casado Arbonies, 2000, t. 1, pp. 129-140; Torremocha, 2012, pp. 219-242). Para el alto clero mexicano sometido, en general, a un esfuerzo de diversificación profesional y a un ascenso lento hacia funciones contiguas, esta exención del cursus hono-

${ }^{1}$ Indiferente, 135, N. 70, 1r. Archivo General de Indias (en adelante AGI), Sevilla, España.

2 Indiferente, 135, N. 70, 3r. AGI, Sevilla, España.

\section{()(1) $(9$}




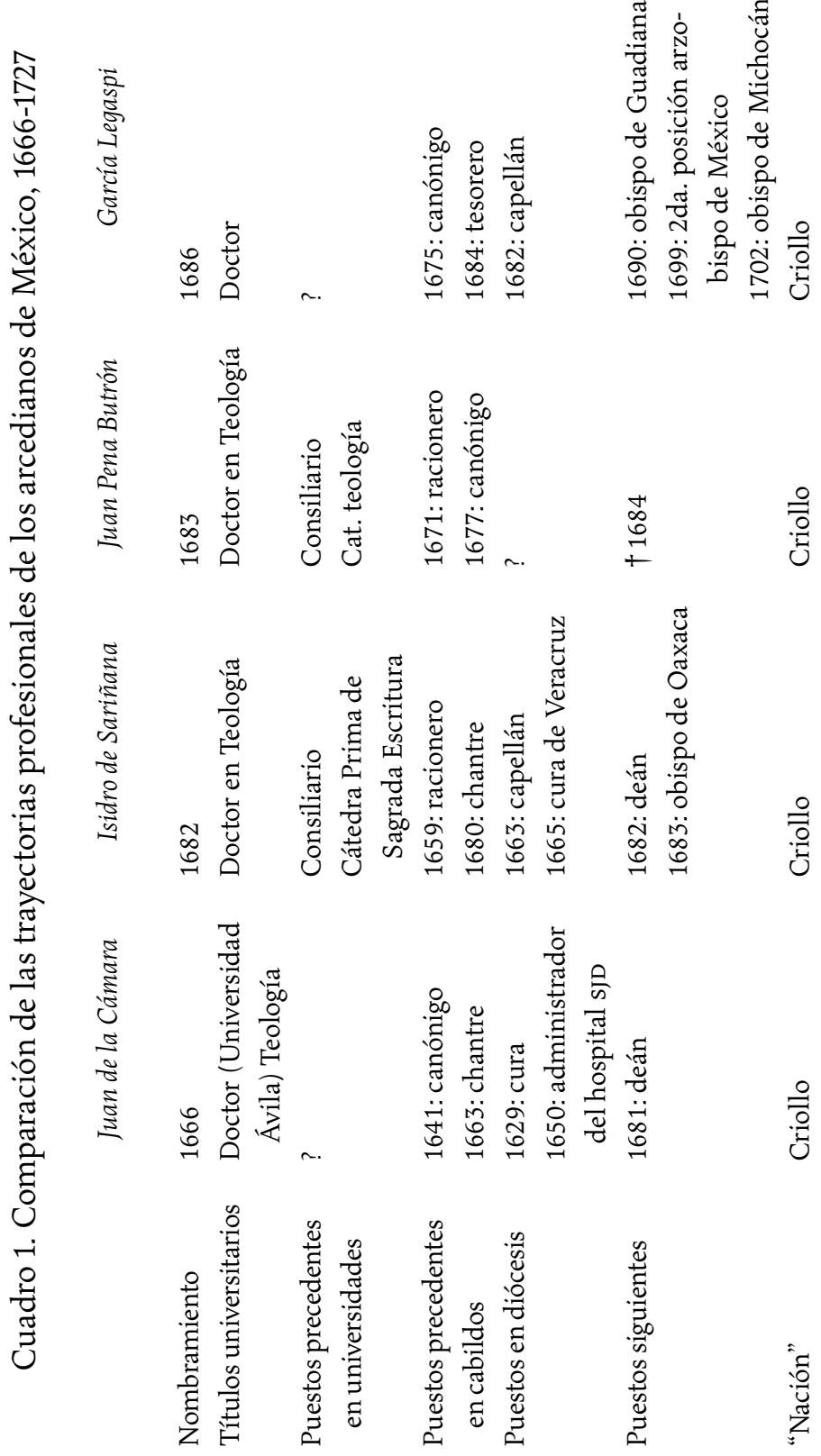

\section{(이)(1)}




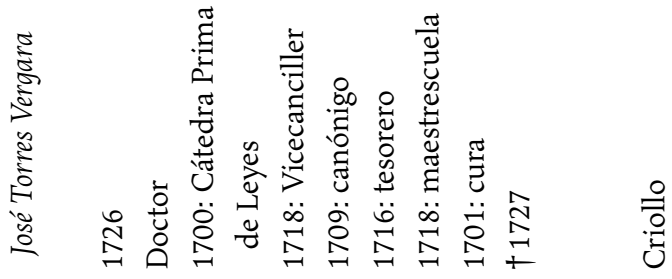

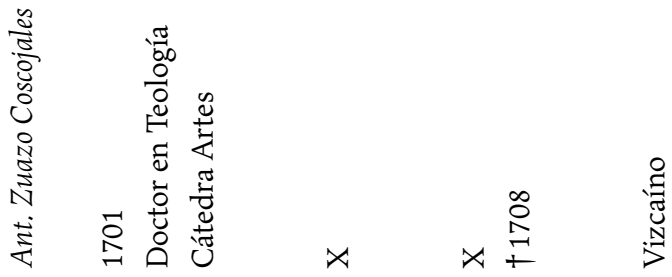

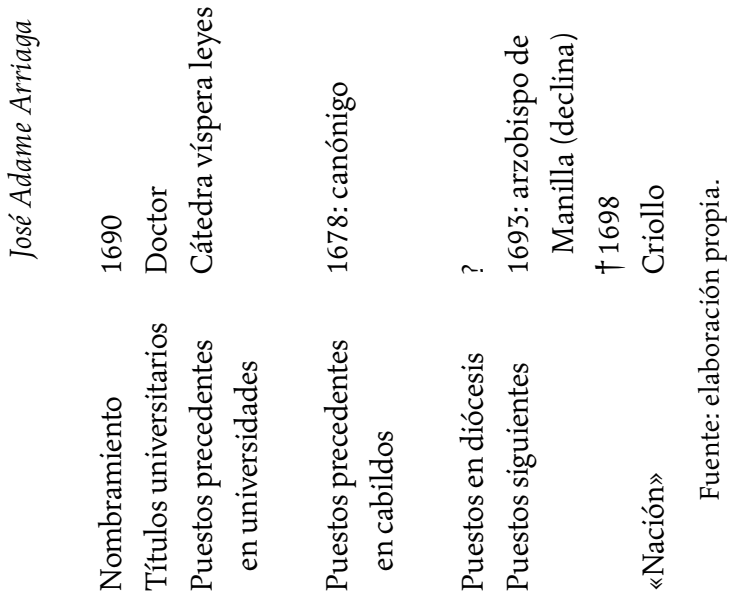

(ㄷ)(1) (8) 
rum clásico aparecía como dispensa inicua, particularmente mal aceptada de parte de un forastero (Aguirre Salvador, 2003; López Quiroz, 1998, p. 105). ${ }^{3}$

A su impopularidad profesional, el vasco sumaba además la desventaja de iniciar su sacerdocio sin la solidez de un arraigo previo en la sociedad local. A nivel social, la condición de recién llegado sometía provisionalmente, fuera de recomendaciones más o menos influyentes según los casos, al aislamiento, a acercamientos interesados e incluso a errores de juicio en las primeras relaciones. Para los altos funcionarios, sobre todo, suponía un déficit de efectividad y una debilidad política en un espacio que se regía entre otras cosas sobre la lógica reticular de la clientela, de la alianza y del clan (Kettering, 1986; Rosenmuller, 2008). Como dignitario de la arquidiócesis y responsable de su administración, la posición de Suazo dependía mucho de su capacidad de movilización. Si bien llevaba consigo de Castilla un doméstico vasco también, ${ }^{4}$ el nuevo arcediano quedaba desvalido sin apoyo local.

Este doble escollo inicial, institucional y social, no era sin embargo inhabitual y remitía más ampliamente a la problemática de la inserción de las elites itinerantes del Estado real en sus dominios dilatados. Común a la mayoría de los altos funcionarios mandados por la corona, en realidad raramente constituyó un obstáculo infranqueable para su integración tanto profesional como social. Diferentes estrategias o posturas, inclusive el tiempo mismo, permitían superar la delicada fase inicial de adaptación y resolver el problema del arraigo. De hecho, a pesar de las numerosas críticas y de las reticencias a nivel local, el Estado real aumentó, en el marco de los esfuerzos reformadores borbónicos, el número de su personal peninsular en Nueva España. Por su parte, el grupo de los ex colegiales mayores siguió alimentando con dirigentes las administraciones reales en América hasta su desaparición al final del siglo.

Dos años antes del nombramiento de Suazo y Coscojales, otro antiguo colegial mayor experimentó estas dificultades iniciales para luego solucionarlas mediante una diplomacia orientada tanto hacia Madrid como México. Cántabro de unos 30 años aproximadamente, José Ibáñez de Lamadrid obtuvo, el 28 de enero de 1700, el cargo de tesorero de la arquidiócesis mexicana, a

${ }^{3}$ Parte de este trabajo se basa en la edición valiosa del manuscrito Fe de erratas, de Pedro de Avendaño, conservada en la Biblioteca del Museo Nacional de Antropología, por López Quiroz (1998), para su tesis de maestría. Viene acompañada de un extenso prólogo que también trata de la controversia, pero desde la perspectiva de sus dos principales protagonistas. Se puede consultar en TESIUNAM.

${ }^{4}$ Contratación, 5460, N. 3, R. 21. AGI, Sevilla, España.

\section{(이요}


pesar de su relativa juventud e inexperiencia clerical como Suazo. ${ }^{5}$ Para obtener su promoción, Ibáñez se benefició, como Suazo, de su condición de ex colegial del San Bartolomé de la Universidad de Salamanca, además, de una recomendación al presidente del Consejo de Indias, Pedro Antonio Núñez de Prado, excolegial mayor también. ${ }^{6}$ Llegado a México con los cajones de la flota de julio (Robles, 1972, t. III, p. 101), el cántabro se enfrentó inmediatamente a la animosidad del Cabildo catedralicio. Vio incluso su nombramiento peligrar por la acción conjunta de varios capitulares. Este dependía pues del doble ascenso de otros dos dignitarios: José Vidal, maestrescuela, tenía que avanzar al puesto de chantre para que Francisco de Aguilar, tesorero, pudiera sucederle y dejar a su vez su dignidad a Ibáñez. Ahora bien, Vidal declinó el 22 de julio su aumento, frenando el movimiento ascendente en el Cabildo y dejando de ese modo al ex colegial de San Bartolomé sin tesorería (Robles, 1972, t. III, p. 103). Incluso la muerte inesperada de Aguilar algunas semanas después, el 20 de agosto, no consiguió abrirle las puertas del Cabildo. Alegando la diferencia entre nombramiento por vacancia y por fallecimiento, los dignitarios mantuvieron su bloqueo.

Frente a la mala voluntad manifestada por el Cabildo catedralicio, Ibáñez de Lamadrid adoptó una doble estrategia, dirigida a la vez hacia Madrid (estrategia de autoridad) y hacia México (estrategia de acercamiento). El eclesiástico recurrió, por una parte, a los órganos centrales de la monarquía y el Estado real ratificó de hecho, algunos meses después, su nombramiento a la tesorería. Ibáñez asumió, por otra parte, una prudente política local de conciliación, pues si la decisión real tenía valor de prescripción indiscutible, no resolvía tensiones ni conflictos. En ese sentido, el eclesiástico trabajó a favor de su integración institucional. Probablemente mediante negociaciones o intrigas internas, consiguió a comienzo del mes de enero ganarse parte del Cabildo. Ante la aversión que le manifestaba en particular el deán, Diego de Malpartida Centeno, con quien se peleó violentamente el 3 de febrero de 1702 dentro de la catedral, el excolegial mayor obtuvo la protección de otra figura del Cabildo, el nuevo chantre Antonio de Anunsibay Anaya. Capitular desde hace más de quince años, el dignitario constituía un aliado de peso, que apadrinó su ceremonia de incorporación a la tesorería el 12 de enero.

De manera más amplia y de manera simultánea a este empeño institucional, Ibáñez obró también para su arraigo social. Para conciliarse la so-

${ }^{5}$ Indiferente, 213, N. 131, f. 9v.; Contratación, 5790, L. 3, F. 319-320. AGI, Sevilla, España.

${ }^{6}$ Indiferente, 213, N. 131. AGI, Sevilla, España.

\section{()(1) $\$$}


ciedad local, el nuevo tesorero decidió simbólicamente realizar su primera misa en México, el domingo 15 de octubre, en el santuario de la Virgen de Guadalupe. Gracias a esos procedimientos, Ibáñez de la Madrid solucionaba, aunque sea en parte, el rechazo inicial a su nombramiento. Capitalizaba también en su provecho la benevolencia urbana. De hecho, cuando Suazo y Coscojales llegó a su vez, el 23 de junio, las tensiones alrededor del nuevo tesorero se hallaban sosegadas. Ibáñez tenía ya superados con éxito los obstáculos iniciales a su integración. El Estado real lo promovió incluso y sin resistencia esa vez, dos años más tarde, en mayo de 1704, a la maestrescolía en sucesión, irónicamente de José Vidal, recientemente fallecido. ${ }^{7}$ Por el contrario, el vasco careció desde el comienzo de su sentido de la circunspección. ${ }^{8}$

Ante las mismas dificultades, Suazo y Coscojales se alineó, conscientemente o no, con otra línea de acción. Mientras Ibáñez favoreció principalmente una fórmula asimiladora, el nuevo arcediano se inclinó en favor de una estrategia de distinción, cuya difusión desdoblada reveló rápidamente sus límites. Remitido a una ilegitimidad profesional por parte del grupo clerical e imposibilitado para apelar al argumento clásico del mérito, el vasco no siguió la vía negociadora de Ibáñez. Optó para compensar su currículo deficiente por un discurso alternativo de autopromoción. Frente a las críticas, Suazo estableció su propia validez profesional sobre la afirmación de una superioridad intelectual personal, que justificó por la calidad de su origen académico, el Colegio Mayor de San Ildefonso de Alcalá. Lejos de articularse sobre la idea de alguna supremacía regional, el discurso del arcediano se fundó sobre la afirmación de una jerarquía universitaria imperial, para nada inédita. Constituía un medio promocional entre otros dentro del amplio repertorio de estrategias elaboradas por los colegiales mayores para asegurar y defender sus ventajas profesionales contra las múltiples críticas que suscitaban. Pero, si bien los argumentos del recién llegado eran audibles en la corte o en algunos sectores de Castilla, no lo eran así en México, que poseía un sólido espacio universitario desde hacía más de 150 años, con vocación hegemónica sobre la región (González González, 2009). De manera contraproducente, la afirmación de superioridad intelectual del vasco sólo podía suscitar la irritación, sobre todo porque el nuevo dignitario no estaba dado a la ponderación. No

${ }^{7}$ Defunciones de españoles, 1693-1714, f. 212v. Asunción Sagrario Metropolitano (en adelante ASM), México.

${ }^{8}$ De Suazo, uno de sus adversarios dirá, con ironía, más tarde que "ancho, grueso, espalducho, y sobre todo con su pie de vizcaíno y su cabeza de lo propio, entró [...] en México" (López Quiroz, 1998, p. 114).

\section{()(1) $\$$}


sólo llegó a calificar por ejemplo el púlpito de la catedral de "inmundo" (Robles, 1972, t. III, p. 256), sino que también reiteró regularmente su voluntad de difundir "en estas partes la Teología de Alcalá" (López Quiroz, 1998, p. 112).9

De manera simultánea, Suazo y Coscojales cometió además un segundo error, probablemente su más grande desacierto. En vez de limitar el alcance de su discurso de supremacía académica únicamente al ámbito erudito, el eclesiástico lo utilizó también para brillar socialmente dentro de los diferentes grupos sociales que comenzó a tratar, gracias a la ayuda de una influyente figura de la capital, Lucas de Careaga. Procedente de Bilbao y sobrino del poderoso mercader Juan de Urrutia Retes, Careaga era un destacado promotor de la identidad vasca en la capital, a través por ejemplo de la confraternidad de la Virgen de Aránzazu, que dirigió como rector en 1702 (Sanchiz, 1997, t. III, pp. 204-215). Ya sea motivado por la solidaridad regional o con base en recomendaciones específicas, alojó en su casa al nuevo arcediano apenas llegado. A partir de esta acogida inicial, los dos compatriotas establecieron una amistad duradera, que llevó incluso al eclesiástico, en abril de 1708 , a designar a Careaga como su heredero. ${ }^{10}$

Exitoso financiero, Lucas de Careaga estaba muy bien integrado a los poderosos sectores mercantiles y mundanos de la capital. Ofreció rápidamente a Suazo la posibilidad de un primer arraigo social. Careaga se encargó pues de introducir en sus diferentes círculos seculares al nuevo dignitario, que al aparecer no rehuía de las mundanidades. Habiendo entrado a México en "traje secular" (Robles, 1972, t. III, p. 223), Suazo gustaba -excesivamente, según sus detractores- moverse en espacios sociales laicos e incluso mixtos, compuestos por auditorios femeninos. ${ }^{11}$ En ellos, el vasco difundió activamente sus declaraciones de superioridad universitarias, esparciendo así su discurso fuera de la esfera erudita y multiplicando inevitablemente su incidencia.

Cuando la afirmación de su excelencia académica le servía, en el espacio intelectual, de argumento para legitimar su ascenso mal aceptado al arcedianato, revestía en otras esferas un sentido diferente. Dentro de los sectores

9 También: "de los mayores sujetos ha dicho de unos que ahora empiezan, de otros que no estudian, de aquellos que no aprietan, de éstos que no hilan y, por último, de todos que no saben; que él daría el modo de predicar de España, y oiríamos y nos enseñaría la teología de Alcalá" (López Quiroz, 1998, p. 115).

${ }^{10}$ Defunciones de españoles, 1693-1714, f. 60v. Asm, México.

11 "muy visitador de señoras y también de señorías" (López Quiroz, 1998, p. 114); "Sobre estas cortesanías y caravanas, dio a entender en algunas conversaciones, principalmente en los estrados de las damas..." (López Quiroz, 1998, p. 114).

\section{()(1) $\$$}


favorecidos a los que Suazo empezó a acceder, la declaración de superioridad intelectual se convirtió más ampliamente en una estrategia de atracción social, que le daba visibilidad y sobre todo un valor distintivo. El arcediano usó de ella probablemente con exceso para asentar su posición todavía inestable de recién llegado. Además, es muy probable que esta declaración fuese reiterada una y otra vez por unos interlocutores socialmente propensos a la conversación y a la discusión.

A la vista de las repercusiones a partir del mes de enero de 1703, ¿qué pudo llevar a un alto funcionario como Suazo a adoptar un comportamiento tan improductivo, en el transcurso de los primeros meses después de su llegada? Primero, hasta entonces simple universitario, el nuevo dignitario sufrió probablemente de su falta de experiencia profesional en materias de gobierno y política. Segundo, su creencia sincera en la superioridad académica de su Colegio Mayor, afianzada durante sus años de estudios, tuvo seguramente un papel importante. Suazo sólo constituyó aquí un agente de difusión, inapropiado y equivocado, de un discurso de supremacía propio de algunos grandes espacios educativos. Tercero, el vasco se vio traicionado probablemente por un temperamento voluble y una alta ambición que lo llevaba incluso, según sus adversarios, a proyectarse como futuro arzobispo de México o virrey de Nueva España (López Quiroz, 1998, p. 246).

Pero sean cuales fueran sus causas profundas, su conducta, destinada a abrirle la capital, tuvo rápidamente dos consecuencias negativas. En primer lugar, Suazo consolidó inevitablemente la antipatía que le tenían parte de sus pares, para quienes el vasco, lejos de justificar su prebenda y sus emolumentos, sólo demostraba arrogancia excesiva. En segundo lugar, al emancipar su discurso del espacio intelectual, el arcediano amplió socialmente el círculo de los implicados. De tal manera, creó un dilatado contexto de especulación. Al tanto, parte de la ciudad esperó con impaciencia su primera prestación pública para medir en la práctica la calidad hasta entonces solamente difundida por el vasco.

\section{RECUPERACIÓN PARCIAL: EL SURGIMIENTO DE LA CUESTIÓN PATRIÓTICA}

Esta tuvo finalmente lugar en la catedral ocho meses después de la llegada de Suazo, el viernes 2 de febrero de 1703, con motivo de la tradicional celebración de la Purificación de la Virgen. El arcediano estaba encargado de pronunciar

\section{()(1) $\$$}


el sermón de la festividad. El auditorio acudió numeroso sin duda, pues no sólo se trataba de la primera aparición pública del dignitario, sino que también la fiesta era por sí misma importante en el calendario litúrgico. Ante la expectación colectiva, el vasco se reiteró doblemente. Justo antes de subir al pulpito, afirmó nuevamente al arzobispo presente que "ahora oirá [V. E.] teología de Alcalá" (Robles, 1972, t. III, p. 256). Luego en el cuerpo del sermón, insistió sobre su procedencia académica. Para demostrar su argumentación, Suazo apeló a una santa autoridad, notoriamente egresada de su Colegio Mayor, Tomas de Villanueva, a quien introdujo además bajo la perspectiva de una estrecha confraternidad estudiantil. En su boca, el santo se convirtió en "mi colegial, gloria y honra de mi Colegio Mayor". Suazo lo invocó incluso directamente como "Hermano, amado mío" (Zuazo y Coscojales, 1703).

Si en general el arcediano predicó bien e incluso moderó en parte la arrogancia personal de sus palabras al concluir finalmente con una insistente muestra de deferencia hacia el Cabildo reunido ${ }^{12}$ su sermón le sirvió de desaire involuntario. Por una parte, su predicación estuvo empañada por un breve momento de turbación en medio del exordio. Por otra, Suazo cometió diversas faltas de latín. Con respecto a la dimensión del sermón, no se trataba de graves deslices. Uno de sus adversarios y gran predicador como Pedro de Avendaño diría, incluso, en cuanto a su confusión pasajera, que "el quedarse un hombre callado en el sermón, no es lo primero del mundo, que a los más doctos les ha sucedido" (López Quiroz, 1998, p. 159). Con respecto a la afirmación de superioridad académica del vasco, sin embargo, sus errores eran inexcusables. Constituyeron un revés público, que alimentó inevitablemente las conversaciones en la capital. Sobre todo, iniciaron un episodio de publicidad que se prolongó durante varios meses y cuya problemática se desplazó rápidamente, pese al arcediano, de la cuestión de las jerarquías académicas imperiales hacia un antagonismo criollo-peninsular.

Los días siguientes, una serie de versos satíricos y burlescos comenzaron a circular clandestinamente en la capital para ridiculizar lo que ya estaba considerado como la estéril arrogancia del eclesiástico (López Quiroz, 1998, pp. 72-103 y 254-256). Diversas recetas, puestas en rimas, se proponían por ejemplo curar la soberbia de Suazo mientras que una octava recomendaba al arcediano:

12 "[confiere sus auxilios la Virgen] a este ilustrísimo cabildo [...]. Especialmente a sus nobilísimos capitulares....” (Zuazo y Coscojales, 1703).

\section{()(1) $\$$}


A ninguno zahieras por tablilla,

Porque es ley de política entablada;

No hagas gestos a nadie, que es mancilla

El que tú quedes feo, sin hacer nada;

De tu lengua ataras la campanilla

No des con ella alguna campanada

Porque no es tan metal el de la trompa

De tu fama, que al punto no se rompa.

López Quiroz (1998, p. 93).

Dentro de esa diversidad de papeles y billetes, una tendencia específica, cuya dimensión es difícil de evaluar, se desprendió, sin embargo, de la burla o embestida en contra de Suazo y Coscojales para tratar de desplazar parcialmente la problemática central de la polémica hacia otra cuestión. Como se ha dicho, la argumentación del arcediano constituía una estrategia, inoportuna y probablemente irreflexiva, de valorización personal, que se destinaba a justificar su presencia en las primeras filas de la arquidiócesis. Vasco emigrado a Castilla, Suazo se fundaba sobre criterios únicamente académicos y, por lo menos según las fuentes consultadas, nunca apeló a argumentos de orden regionalista. Sin embargo, una parte de la literatura satírica sobre el eclesiástico se dedicó rápidamente a sustraer a la disputa su carácter singular para imponer el elemento patriótico. ${ }^{13}$

Primero, la figura del arcediano se vio desprovista de su individualidad para asimilarse a un grupo peninsular, del cual apareció presentado como el campeón. Luego, su discurso de superioridad erudita se convirtió en una prueba de ingratitud generalizada y de desprecio colectivo, si no de aversión, para la generosa tierra de acogida novohispana de parte de altas notabilidades originarias de la península. De tal manera, se desplazó en parte la polémica del terreno de la rivalidad académica hacia la oposición entre criollos y peninsulares. Lejos de ser enteramente espontánea o irreflexiva, esta transformación de la problemática inicial ensanchaba el círculo de individuos involucrados hasta el momento. Sobre todo, cubría de oprobio a los adversarios declarados de un influyente partido de la capital, cuya figura principal y uno de los principales patrones era el agustino Diego Velázquez de la Cadena.

${ }^{13}$ Para otra interpretación historiográfica del episodio, véase Herrera (2009); López Quiroz (1996).

\section{()(1) $\$$}


Originario de la capital, el regular era un miembro eminente de un poderoso linaje, los Velázquez de la Cadena, cuya nebulosa de aliados, partidarios y clientes se extendía a varios sectores claves del virreinato (Rubial García, 1990, pp. 64 y 183). En cuanto segundón, el novohispano fue mandado joven hacia las Órdenes para convertirse en un dignitario de la provincia agustina de México, en un ambiente tenso por la alternancia impuesta entre las facciones criollas y peninsulares. La desaparición de Hernando de Sosa, en febrero de 1682, le permitió alzarse al frente del grupo dirigente criollo. El agustino asentó entonces duraderamente su dominio sobre la provincia y sus recursos a través del tráfico de influencias, el reparto de los prioratos o el pago directo de importantes sumas, que alimentaban la alianza y fidelidad de redes de clientelas y seguidores. Además de valerle el apodo de monarca criollo, esta efectividad política y amplitud social le permitían neutralizar las acusaciones de fraude electoral y corrupción levantadas contra él por el grupo peninsular, apoyado por reformadores novohispanos que rompían con una oposición estrictamente regionalista.

Cuando, a finales del mes de junio de 1702, Suazo y Coscojales llegó a México, Velázquez de la Cadena acababa de ser elegido provincial por segunda vez, el jueves 4 de mayo, en sucesión de Gaspar Ramos, testaferro peninsular al servicio del dignitario (Rubial García, 1990, pp. 64-65). Enfrentado a las mismas acusaciones de corrupción, la situación del novohispano estaba sin embargo menos favorable que antes. En primer lugar, la muerte de su hermano mayor, exgobernador de gobierno, el 6 de febrero de 1697, dejó debilitado el linaje al disminuir su arraigo en la corte. En segundo lugar, la ida de Manuel de Escalante y Mendoza, nuevo obispo de Durango, para su diócesis el 14 de noviembre de 1701, privó al clan de los Velázquez de la Cadena de un estratégico aliado, particularmente poderoso dentro de las altas instancias de la arquidiócesis. En tercer lugar, el prelado titular, Ortega y Montañés, no tenía simpatía particular por el agustino. Había redactado, en julio de 1673, un expediente sobre la situación de la provincia para la reina, que atestaba de las prácticas de corrupción sistemática del grupo dirigente criollo. Por lo tanto, el arzobispo estaba bien informado de las maquinaciones y tensiones dentro de la orden. En ese contexto, el nuevo provincial lanzó entonces una campaña de comunicación para silenciar las críticas y legitimar su nuevo gobierno. Precisamente, la polémica suscitada por Suazo y Coscojales ofreció una oportunidad ideal.

De los meses que siguieron a su reelección hasta febrero de 1703 y el arranque de la controversia, los más vindicativos opositores de Velázquez de

\section{()(1) $\$$}


la Cadena fueron los miembros de la facción peninsular de la provincia, que Cadena y los suyos habían logrado excluir de la gobernación provincial desde las elecciones de mayo de 1696 (Rubial García, 1990, pp. 62-65; Ruiz Zavala, 1984, t. II, p. 504). Dirigido por el castellano Antonio Gutiérrez, último provincial del partido peninsular durante el trienio de 1693-1696, el grupo era particularmente peligroso gracias a sus conexiones en Madrid o Roma y por el contenido de su argumentación. Lejos de ser de orden regionalista, sus ataques contra Cadena se basaban sobre la reiteración de acusaciones de corrupción, si no de violencia. Porque presentaba al agustino como una barrera para el cumplimento del ideal evangélico, la crítica era eficazmente perjudicial. Sin embargo, Suazo ofreció precisamente una ocasión inesperada de reacción a Velázquez de la Cadena, que se arrojó oportunamente en la polémica producida por el vasco. El arcediano proporcionaba al agustino dos importantes recursos: por una parte, la atención pública que suponía el episodio de publicidad suscitado por Suazo y, por otra, la posibilidad de valerse del sentimiento particularmente inclusivo y movilizador del patriotismo. Bien manipulados, estos dos elementos permitieron un contraataque eficaz al discurso del primer grupo detractor del novohispano y de su facción.

A la edad de 65 años, Velázquez de la Cadena era, a diferencia del vasco, un táctico experimentado, que dominaba perfectamente los mecanismos del juego político. En los días que siguieron el sermón de Suazo, asoció la facción agustina enemiga con el arcediano al hacer circular, sobre la oleada de la polémica, falsas acusaciones de antipatriotismo. En uno de los versos que se difundieron, el grupo de Antonio Gutiérrez apareció a la vez como el cómplice del arcediano, representante peninsular de la elocuencia, y como un auditorio ganado:

Con gran prevención

Juzga de Europa el común

Que había de orar como un

Elocuente Cicerón;

Y en gloria de su nación

Todo honrado galopín

A punto el postre y de ruin

Se convocó - vive san!-

Para aplaudir a su gran

Orador ultramarín,

Vino de San Agustín, 
El nacional borbollón:

De Gutiérrez fray Antón, Ruiz, Ramos, Ponce y Fermín

López Quiroz (1998, p. 75). ${ }^{14}$

La alegación era no obstante doblemente engañosa. Primero, Gaspar Ramos, si bien era asturiano, era también criatura de Velázquez de la Cadena que lo utilizó como testaferro para mantener el control de la provincial durante el trienio de 1699-1702. El regular no representaba pues a ningún partido peninsular. Segundo, Antonio Gutiérrez desmentiría él mismo el mes siguiente con vigor e insistencia el haberse desplazado para escuchar la predicación del vasco. ${ }^{15}$ Aunque falsa, esta implicación comunicada al público urbano permitía proyectar públicamente sobre la facción agustina peninsular el reproche de arrogancia e ingratitud. Un aliado activo de Velázquez de la Cadena, su pariente y personalidad intelectual ineludible en el virreinato, el eclesiástico Pedro de Avendaño, escribió sobre Gutiérrez que:

la que este reverendo padre [Antonio Gutiérrez] tiene con la nación criolla habría menester muchos jueves santos para llorarla; no hay por acá hombre para su paternidad que sea blanco, ingenio que sea agudo, nobleza que sea limpia, proceder que sea honrado, casa que sea solariega, prendas que sean cabales, estudiante que sea docto, ni nada que sea algo... (López Quiroz, 1998, p. 137). ${ }^{16}$

La afirmación era igualmente infundada, tanto a la vista de los discursos políticos del castellano como por su sociabilidad. Dentro de la orden, en primer lugar, la política llevada por Gutiérrez no corroboraba las palabras de Avendaño. Al contrario, las invalidaba. Para el castellano, o al menos según sus discursos, el punto primordial era la reforma moral de la provincia.

${ }^{14}$ Se trata de los agustinos peninsulares Antonio Gutiérrez, Gaspar Ramos, Juan Fermín Armendáriz.

15 "me halle preocupado del sentimiento de no haber asistido oyente este día, defraudado del gusto de oir en voz del predicador lo que he visto y admirado en su papel" (Antonio Gutiérrez, "Parecer". En Suazo y Coscojoles, 1703, f. 4r.); "el sentimiento de no haber oído" (Antonio Gutiérrez, "Parecer". En Suazo y Coscojoles, 1703, f. 4v.); "lo que no oyeron gustosos o tuvieron, como yo, la desgracia de ausentes" (Antonio Gutiérrez, "Parecer". En Suazo y Coscojoles, 1703, f. 4v.).

${ }^{16}$ También: "no lo sienta la tierra (y en verdad que la tierra está bien sentida con su paternidad)" (López Quiroz, 1998, p. 137); "como nuestro padre Gutiérrez es tan castellano y viejo, nos peina de modo el estilo, que los que no sabemos acá...” (López Quiroz, 1998, p. 141).

\section{()(1) $\$$}


La alternancia no constituía la afirmación de una superioridad peninsular ni de una inferioridad novohispana, sino un mecanismo indispensable de rotación de las elites dirigentes, capaz de detener el arraigo de los fenómenos de clientelismo y corrupción. De esa manera, no sólo Gutiérrez se aliaba con sus correligionarios peninsulares o criollos con tal que compartieran su voluntad reformadora, como Bartolomé Gil Guerrero quien finalmente lo traicionaría, sino que también no dudó en tomar la pluma para escribir, en 1682, al Estado Real en favor de los "peninsulares y criollos beneméritos" de Nueva España, víctimas por igual, según él, de la degradación ética de la provincia (Rubial García, 1990, p. 56). ${ }^{17}$

En el ámbito del espacio intelectual de la capital, en segundo lugar, Gutiérrez estaba también muy alejado de manifestar un exclusivismo regional, de carácter propeninsular, o alguna repulsión visible hacia sus pares novohispanos. Según las licencias de publicación, el agustino parece al contrario favorablemente arraigado en la intelectualidad local, tanto antes como después de la polémica y de manera cuantitativa como cualitativa. En términos numéricos, las numerosas relaciones eruditas ostensibles del castellano eran casi todas novohispanas (véase diagrama 1). Todas las aprobaciones que firmó Gutiérrez entre 1680 y 1711 iban destinadas a criollos y, de sus cocensores, nueve eran novohispanos frente a sólo dos peninsulares. En términos cualitativos, dentro de las conexiones intelectuales novohispanas del agustino se encontraban importantes personalidades eclesiásticas, seculares y regulares. En octubre de 1696, por ejemplo, Juan Millán de Poblete, racionero del Cabildo e hijo de una respetada familia novohispana, solicitó a Gutiérrez que le redactara una aprobación (Millán de Poblete, 1696). ${ }^{18}$ El 9 de agosto de 1711, ocho años después de la controversia, fue el antiguo provincial de la provincia franciscana y examinador sinodal de la nunciatura de España, Manuel de Argüello, quien se dirigió a su vez hacia el castellano (Argüello, 1711).

Las relaciones intelectuales de Gutiérrez podían obviamente deberse en parte a una diplomacia necesaria o a maniobras políticas impuestas a un

${ }^{17}$ Siempre en contra de las acusaciones de Avendaño, un íntimo de Gutiérrez, José de Sicardo, manifestó su reticencia al envío de religiosos procedentes de la Provincia de Andalucía, a pesar de un contexto demográfico desfavorables para los peninsulares en Nueva España. Sicardo favoreció a sus correligionarios de la Provincia castellana, para evitar la constitución de una tercera facción en la Provincia (Rubial García, 1990, p. 60).

${ }^{18}$ Dos tíos de Juan Millán fueron arzobispos de Filipinas, José Millán de Poblete y Miguel de Poblete. Otro familiar, Juan de Poblete, renunció al obispado de Cagayán y al arzobispado de Filipinas.

\section{()(1) $\$$}




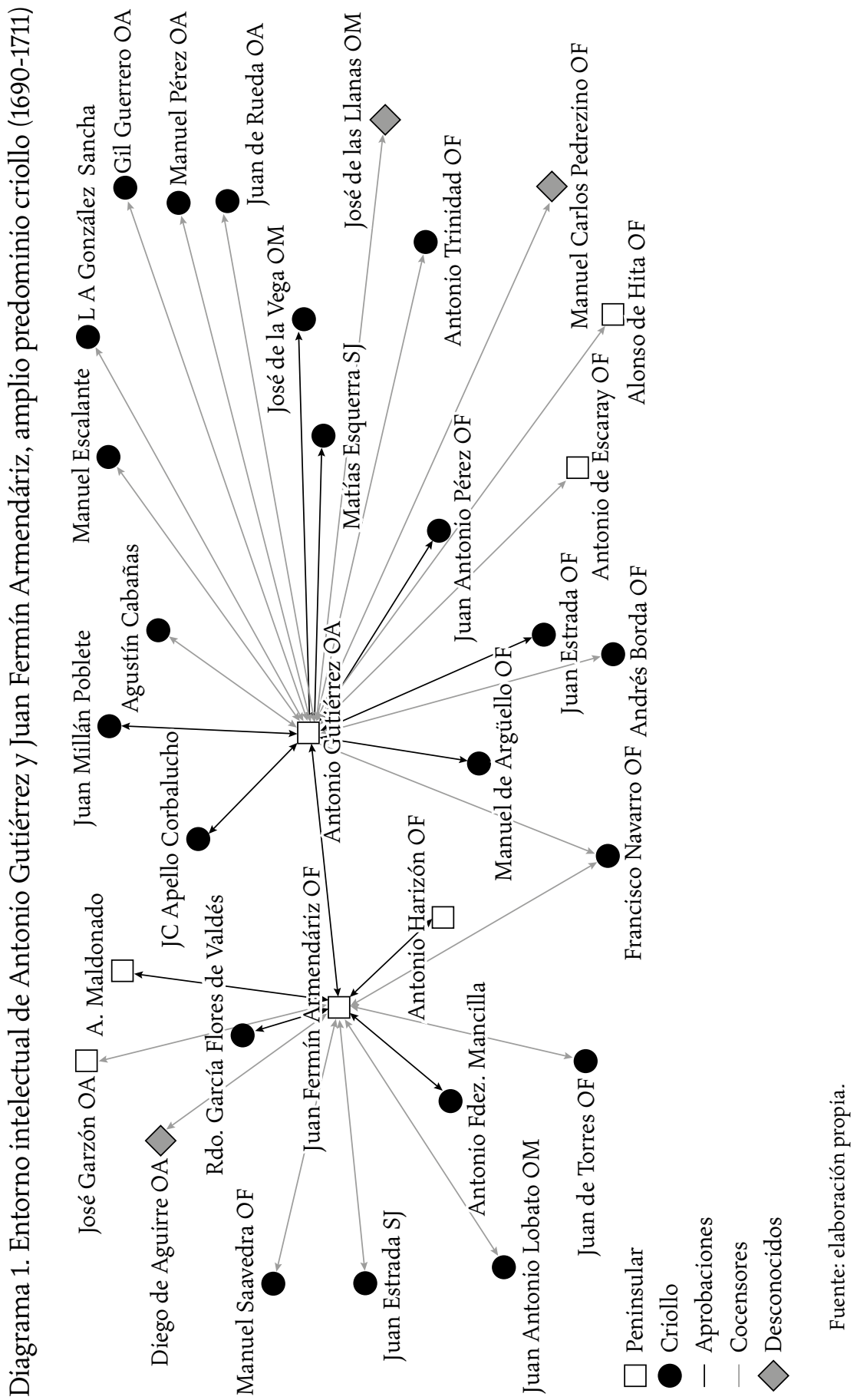

\section{(이요 $\$$}


jefe de facción, en desventaja demográfica, que disimulaban su rechazo visceral a la tierra novohispana. Sin embargo, parece poco probable que notabilidades criollas establecidas se hayan asociado, aunque sea puntualmente, con un individuo capaz de repudiar tan radicalmente, según Avendaño, una sociedad local de la que eran los hijos privilegiados. La sociabilidad intelectual, heterogénea e inclusiva de Gutiérrez no era además única dentro del grupo peninsular agustino. Un lugarteniente del castellano, Juan Fermín de Armendáriz, la compartía también (véase diagrama 1). Sobre todo, algunas de las relaciones criollas de Antonio Gutiérrez procedían de amistades ostensibles, que desbordaban indiscutiblemente del marco político o estratégico. El castellano afirmó, por ejemplo, en agosto de 1711, considerarse "amigo íntimo del R[everen]do Predicador" Manuel de Argüello (Argüello, 1711, f. 12v.). Reconoció incluso, nuevamente en contra de las acusaciones de Avendaño, su admiración intelectual "desde que estudiaba [Argüello] gramática" (Argüello, 1711, f. 12r.). El franciscano era no obstante un promotor convencido de un discurso patriótico y, de hecho, fue para la publicación de un panegírico de la Virgen de Guadalupe que Argüello invitó a Gutiérrez a suscribirle una aprobación.

De manera comparable a la situación del sector financiero, de los altos mercaderes a los oficiales reales (Bertrand, 1999; Huerta, 1997; Lohman Villena, 1974), el arraigo intelectual de Gutiérrez o Armendáriz manifiesta lo poco pertinente, en su caso, de la distinción entre criollos y peninsulares. Tal como para el mundo novohispano de las finanzas, la sociabilidad de los agustinos peninsulares descansaba sin duda más sobre las lógicas de alianzas, duraderas y circunstanciales, o afinidades eruditas que sobre una solidaridad metropolitana, por lo demás seguramente mínima frente a la diversidad conflictiva de las identidades regionales en la península. En ese sentido, las acusaciones de desprecio a lo novohispano, llevadas en contra de Antonio Gutiérrez y los suyos, tienden a invalidarse para revelarse más bien como parte de un movimiento político orquestado por su principal adversario, Cadena, con base al argumento del patriotismo ofendido y con el objetivo de dirigir en su contra la opinión pública de la capital.

No era la primera vez que Velázquez de la Cadena recurría al patriotismo como arma política. Además de usarlo en la provincia para reivindicar la preeminencia de su facción, el agustino no dudó tampoco en instrumentalizarlo, en abril de 1688, en el espacio universitario para deshacerse, sin éxito, de un contrincante. El 9 de enero de 1688, durante una reunión del claustro para la atribución anual de los cargos, el agustino perdió, a pesar de su insistencia y de vivos debates, el cargo de examinador en beneficio de José de

\section{(1)(1)}


Herrera, criollo de la Orden de Santo Domingo (Carreño, 1963, t. I, p. 323). Lejos de darse por vencido, Velázquez de la Cadena siguió maniobrando y obtuvo, el 20 de marzo, el traslado del dominico a la procuraduría para recuperar su cargo. Desgraciadamente para el agustino, el voto en favor de Herrera se vio anulado quince días después, en favor del candidato del rector el doctor Francisco López de Sosa, peninsular. En reacción, Cadena inició una campaña en su contra, que ancló en el criterio del patriotismo y de la preferencia criolla. ${ }^{19}$ Pero como candidato de un rector también criollo, López de Sosa conservó mayoritariamente el apoyo de los universitarios. Cadena tuvo finalmente que esperar un año y la elevación a la diputación de hacienda de Herrera para alcanzar el cargo de examinador.

Si bien el procedimiento no era inédito, el interés de la polémica descansa sobre la instrumentalización del patriotismo en un amplio escenario urbano y no únicamente dentro de las esferas cerradas de las instituciones agustinas y universitarias. Para el partido de Cadena y su situación a comienzo de 1703, el procedimiento ofrecía una doble ventaja. En primer lugar, el argumento patriótico tenía, porque era comprensible para todos, una gran capacidad de resonancia y una gran fuerza movilizadora. Al llamar al sentimiento patrio, Cadena y sus partidarios aumentaban al público la polémica. De esa manera, extendían incluso puntualmente el espacio público de la capital. En segundo lugar, su instrumentalización permitía dirigir en contra de Antonio Gutiérrez y de su grupo una desaprobación colectiva, de alto costo político y que neutralizaba en parte el impacto de sus discursos contra el monarca en la capital. Ante el impacto potencial de las acusaciones, el castellano estuvo obligado a reaccionar rápidamente y a entrar en la polémica, movilizando sus redes de aliados y la prensa.

\section{REACCIONES Y CONTRAGOLPES: EL AFIANZAMIENTO DEFINITIVO DE LA CUESTIÓN PATRIÓTICA}

Quince días después del sermón de Suazo, el grupo liderado por el castellano inició un contraataque constituido de una vertiente defensiva y de otra ofensiva. Acusados públicamente de desprecio a la región, la respuesta de

19 Según el virrey: "se embarazan ahora [las elecciones del procurador] en si ha de ser gachupín o criollo el procurador”, citado en Carreño (1963, t. I, p. 324).

\section{()(1) $\$$}


los agustinos de Gutiérrez pasó por un canal capaz de alcanzar a su vez un auditorio amplio: la imprenta. Gracias al apoyo de amigos y aliados, los regulares se invitaron, en primer lugar, en diferentes publicaciones prestigiosas en las que emplearon los paratextos obligatorios, espacios de opinión o tribunas públicas, para difundir un alegato de inocencia, defendiéndose de cualquier acusación de desconsideración. Aunque a los 61 años nunca antes haya redactado aprobaciones en la capital, ${ }^{20}$ fue la mano derecha de Gutiérrez, Juan Fermín de Armendáriz, quien se encargó de este aspecto inicial de respuesta a Velázquez de la Cadena. El agustino inauguró en este sentido, a mediados del mes de febrero, una intensa e inédita actividad de censor destinada a convencer de la calidad de sus lazos y de su gratitud hacia la sociedad novohispana.

Armendáriz apareció primero, el 15 de febrero, en la publicación de un panegírico a la Inmaculada Concepción pronunciado en la universidad, bastión de la intelectualidad local. La publicación estaba financiada además por el rector en persona, Juan de Ignacio y Castorena, notoria figura novohispana. En el "parecer" que firmó para el autor, el franciscano novohispano Francisco de Navarro, el agustino dio fe de su agradecimiento con una ciudad en la que residía desde hacía más de diez años y "[su] gratitud dice a la Imperial Ciudad de México [...] lo que Lucano dezia de Roma cuando la desseaba prospera" (Navarro, 1703, f. 3r.). Armendáriz se repitió luego tres meses más tarde, el 10 de mayo, en una aprobación destinada esta vez a la publicación del carmelita descalzo, Andrés de San Miguel, novohispano también. Con más claridad todavía, el regular afirmó nuevamente: "tener muy presente los beneficios que recibí veinte y cinco años ha en la Ciudad de Puebla de los Padres, y Hermanos del Autor, hallándome pobre de todas maneras, Lector de Theologia y forastero, [...] y me persuado, que supuesto lo recibido [...] mejoraré mi agradecimiento" (San Miguel, 1703, f. 3r.).

Finalmente, el lugarteniente de Gutiérrez prosiguió una última vez, el 23 de junio, su campaña de comunicación. Firmó una elogiosa aprobación para otro novohispano notorio, hijo de un regidor de la capital, el franciscano Antonio Fernández de Manzilla, con motivo de la publicación de un panegírico encargado por la orden religiosa americana por excelencia, la Orden Hospitalaria de los Bethlemitas.

${ }^{20}$ Armendáriz entró en la Orden en Pamplona. Se registra en junio de 1667 en la Casa de la Contratación. Según los datos que informó, nació en 1642. Véase Contratación, 5441, N. 2, R. 17, f. 1r. AGI, Sevilla, España.

\section{()(1) $\$$}


De manera simultánea a esta fase de refutación, la facción peninsular agustina lanzó, a comienzos de marzo, una segunda operación, más agresiva esta vez, pero siempre a través de la prensa. Con Gutiérrez, quien firmó la primera aprobación el 8 de marzo, y Juan Fermín de Armendáriz, que se encargó del manuscrito y de sus pruebas, los agustinos impulsaron activamente la publicación del criticado sermón de Suazo y Coscojales, que llegó a las librerías por el mes de mayo.

Con respecto a las fuentes disponibles, es difícil determinar cómo nació la idea de publicar el panegírico del arcediano. ¿Fue un proyecto concebido por su autor, contrariado de haber sido ridiculizado en la capital, quien lo propuso a los agustinos peninsulares, en cuanto víctimas colaterales de la efervescencia satírica de febrero? ¿O bien resultó de una iniciativa propuesta por Gutiérrez y sus aliados a Suazo? Para el bando de Velázquez de la Cadena, el instigador del proyecto fue sin duda el agustino, tal como lo afirmó otro verso satírico, difundido después de la publicación de la obra:

Dice el padre fray Antón

De aqueste sermón de Borra,

Que para que a todos corra

Será buena la impresión;

Venimos en su opinión

Pero de este modo sea:

Que cualquiera al punto vea

Que en este sermón ha sido

Del Arcediano el corrido

Y del Padre la correa

López Quiroz (1998, p. 153).

Como sea, esta alianza circunstancial se prolongó en el tiempo y Juan Fermín de Armendáriz formó parte algunos años más tarde de los albaceas del vasco. ${ }^{21}$ Juntos, estos nuevos socios prepararon cuidadosamente la publicación del texto del sermón hasta los diferentes paratextos. Gutiérrez suscribió la primera aprobación para negar con insistencia su presencia durante el sermón del 2 de febrero. Tres veces y a través del artificio retórico de la ausen-

${ }^{21}$ Defunciones de españoles 1693-1714, f. 66r. ASM, México.

\section{(ㅇ)(1) $\$$}


cia lamentada ${ }^{22}$ el castellano invalidó los versos clandestinos que lo habían señalado como parte del auditorio. El provincial de la provincia franciscana de Zacatecas, el castellano Luis Antonio Hermoso de Solís, firmó la segunda aprobación, al "parecer" virulento y particularmente ácido. De paso en México después de una estancia en Roma, ${ }^{23}$ el eclesiástico se vio probablemente implicado en cuanto alto dignitario peninsular. Dedicó la parte final de su texto a denunciar violentamente a los comentadores y panfletistas anónimos de febrero. ${ }^{24}$ Sobre todo, la obra se consagró a la figura de la virreina, la duquesa de Albuquerque, a través de una larga dedicatoria, redactada por Suazo, que funcionó como una manifestación de autoridad y potencia.

Los dos procedimientos empleados por el grupo de Gutiérrez, firmar aprobaciones y publicar, no eran para nada inéditos en México y tienen que ver de manera más general con la problemática, no tratada aquí, de la opinión pública. ${ }^{25}$ Entre otros ejemplos, en 1681, el orador franciscano Antonio de Escaray utilizó la dedicatoria de su primera publicación en la capital para responder públicamente a las acusaciones de imitación de las que era objeto (Escaray, 1681). El eclesiástico Pedro de Avendaño sometió, por su parte, varias veces, publicaciones enteras a un calculado esfuerzo de comunicación (en particular: Avendaño, 1699). En el caso de los agustinos y del contexto de 1703, estas diligencias ofrecían beneficios distintos. Por una parte, las diferentes aprobaciones firmadas por Armendáriz difundían una respuesta pública a las acusaciones formuladas contra su facción, destinada a desactivar la perspectiva patriótica promocionada por Cadena. Por otra parte, la publicación del sermón de Suazo funcionaba, bajo la tutela de la virreina, como una verdadera demostración de fuerza y legitimidad en el espacio público. Ante la obra, los detractores del arcediano, como Velázquez de la Cadena y

22 "me halle preocupado del sentimiento de no haber asistido oyente este día, defraudado del gusto de oir en voz del predicador lo que he visto y admirado en su papel" (Antonio Gutiérrez, "Parecer". En Suazo y Coscojoles, 1703, f. 4r.); "el sentimiento de no haber oído" (Antonio Gutiérrez, "Parecer". En Suazo y Coscojoles, 1703, f. 4v.); "lo que no oyeron gustosos o tuvieron, como yo, la desgracia de ausentes" (Antonio Gutiérrez, "Parecer". En Suazo y Coscojoles, 1703, f. 4 v.).

${ }^{23}$ Contratación, 5460, N. 2, R. 17. AgI, Sevilla, España.

24 "quemar y purificar labios que han de hablar y escribir acerca de los sermones [...] de la Purificación" (Luis Antonio Hermoso de Solís, "Parecer". En Suazo y Coscojales, 1703, f. 7r.); "labios que se han de ocupar en hablar de tales oraciones purificadas, necesitan para su purificación de repetidos sagrados fuego..." (Luis Antonio Hermoso de Solís, "Parecer". En Suazo y Coscojales, 1703, f. 7r.).

${ }^{25}$ Sobre la opinión pública en la Nueva España, véase Silva Prada (2007); Torres Puga (2010).

\section{()(1) $\$$}


los suyos, aparecían a los ojos de la ciudad bajo un estatuto de rivales menores y clandestinos. Para un individuo de la envergadura del agustino, que alimentaba en parte su eficacia política de la dimensión de su prestigio urbano, la publicación constituía un golpe público que atentaba a su prestigio y que no podía dejar pasar.

Velázquez de la Cadena replicó rápidamente. A pesar de las denegaciones públicas de los agustinos peninsulares, decidió de manera estratégica insistir nuevamente e incluso con más fuerza sobre la cuestión patriótica. El monarca recurrió a la talentosa pluma de un pariente suyo, Pedro de Avendaño, que redactó lo que constituyó la pieza central de la polémica, la Fe de erratas. Orador muy apreciado, Avendaño era entonces un hombre de letras ineludible en la capital, pese a una trayectoria profesional contrariada por su expulsión de la Compañía de Jesús en octubre de 1690 (Laske, 2015). Por parte de su tía, Juana de Soussa, el eclesiástico era primo político de los Velázquez de la Cadena, que no dudaron en varias ocasiones en ayudar a su pariente y su carrera. Marginado profesionalmente en la arquidiócesis por su expulsión de los jesuitas, Avendaño no había de tener inicialmente mucha simpatía para Suazo y Coscojales, su hoja de servicio mediocre y su arrogancia. Tal como lo escribió, ${ }^{26}$ el antiguo jesuita no suscribía, sin embargo, a los discursos patrióticos. De hecho, mantenía relaciones estrechas con importantes personalidades peninsulares, como el precedente virrey, el conde de Moctezuma, que llegó a recomendarlo a la corona. Pero, pese a ello, para asistir a un pariente cercano y a su propio clan, Avendaño aceptó producir un texto cargado de un patriotismo manifiesto.

A través de un largo comentario linear de la publicación de Suazo y Coscojales, el eclesiástico volvió a impulsar, de dos maneras, la lectura de la polémica promovida por su primo. Por una parte y de manera general, Avendaño recondujo la división de los protagonistas entre novohispanos, "hijos de la región", y peninsulares, "los de España" (López Quiroz, 1998, p. 201). Bajo su pluma, la arrogancia universitaria y erudita de Suazo representaba la inaceptable afrenta de un peninsular en contra de la intelectualidad novohispana y de la que se hacía el defensor autoproclamado. ${ }^{27}$ Por otra parte

\footnotetext{
26 "a la verdad nunca he gustado de un espíritu q[ue] llaman nacional" (Avendaño, "Parecer”. En San Miguel, 1703, f. 6r.).

${ }^{27}$ Véase por ejemplo: "no es razón que este caballero haya venido a hacer común desprecio de los sujetos grandes deste emporio, sin que haya algunos de los mínimos y menores, cual soy yo y mis compañeros, que lo refrenen, para que en adelante calle" (López Quiroz, 1998, p. 250. También, pp. 112 y 116).
}

\section{()(1) $\$$}


y de manera más específica, Avendaño reiteró vigorosamente en su texto las acusaciones de aversión e ingratitud hacia la sociedad local que ya se habían imputado a Suazo y Gutiérrez. Remitió el primero a su falta de consideración para su dignidad y culpó al segundo de una declarada repugnancia hacia la región. ${ }^{28}$

A la vista de la claridad del texto y según las palabras de su autor (López Quiroz, 1998, p. 113), la Fe de erratas se destinó a un amplio público en la capital. Velázquez de la Cadena disponía de los medios necesarios para asegurarle una vasta difusión. Es probable que el agustino empleara varios copistas para poner en circulación una cantidad importante de ejemplares, lo cual explicaría hipotéticamente el número importante de versiones hoy en día conservadas para este tipo de documento. Las copias comenzaron probablemente a difundirse durante el mes de junio y, con base en tres resortes, capitalizaron muy rápidamente un gran éxito en México. Primero, al suscribir al registro de la contienda literaria, la propagación de la Fe de erratas se beneficiaba del interés y gusto urbano por el género de la disputa. Segundo, la eficacia y brillantez de la escritura de Avendaño en sí misma, la calidad argumentativa de su pluma, constituían otro factor favorable de difusión, de orden formal. Tercero, y de manera similar a los primeros versos que implicaron a los agustinos peninsulares, la llamada de Avendaño al sentimiento patrio contribuyó también a ampliar el espectro de los receptores.

Con la amplitud de su éxito, el texto del predicador silenció y anuló por completo los esfuerzos de comunicación hasta ahora realizados por los agustinos peninsulares para convencer a la capital de su inocencia. Al contrario, la Fe de erratas terminó de asentar definitivamente, dentro del espacio público, la controversia en el terreno del patriotismo. De hecho, en 1777 y en el contexto de un patriotismo más defensivo debido a las reformas borbónicas, sus copias seguían circulando en los círculos de una elite erudita novohispana como una literatura de agradable diversión, manifestación de la victoria intelectual de un docto criollo sobre un par peninsular. ${ }^{29}$

${ }^{28}$ Por ejemplos: "para que Vuestra Merced esté gustoso, póngase delante los ojos los grandes sujetos que han ocupado la silla de su dignidad" (López Quiroz, 1998, p. 246); "contentándose y dando a Dios mil gracias de estar en una región de una tan alta silla, de que se ven privados tantos méritos como tienen los hijos de la misma región, que lloran olvidados..." (López Quiroz, 1998 p. 250. También p. 137).

${ }^{29}$ Inquisición. Vol. 1169, exp. 2, f. 15. Archivo General de la Nación (en adelante AGN), México.

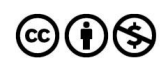




\section{EPÍLOGO: UNA INTEGRACIÓN RENOVADA}

Después de un nuevo sermón de Suazo y Coscojales el 15 de agosto en la catedral, varios pasquines e incluso una denuncia al Santo Oficio, ${ }^{30}$ la controversia se apagó en el escenario urbano con una última intervención pública de Suazo el 19 de noviembre. Frente a una polémica que lo rebasó rápidamente, Suazo se vio finalmente obligado, pese a no ser su intención inicial entrar en cuestiones de regionalismos, a dirigirse a la ciudad para denegar a su vez públicamente el atentar contra la generosidad de la tierra novohispana. El arcediano procedió de la misma manera que los agustinos peninsulares: a través de las prensas. Beneficiándose de las conexiones e intereses compartidos en la capital entre la comunidad vasca y la orden franciscana, se incorporó al proceso de publicación de dos sermones de la cofradía de Aránzazu, establecida en la Iglesia franciscana y cuyo rector era precisamente su amigo Careaga. Suazo firmó una de las censuras de la nueva publicación de la asociación de piedad y empleó parte de su paratexto para lanzar en el espacio público un mensaje apaciguador. De manera explícita, manifestó su satisfacción profesional y su gratitud:

En aquel país [vasco] tuve el ser, y la primera educación; en las tres universidades mayores de España los grados; y en esta Metropolitana Iglesia la Prebenda que gozo, essos son de mi vida los pasos, pues digo con más verdad [...] que no voy a parte donde no encuentre de María de Begoña, y de Aránzazu beneficios; bien reconozco imposible el agradecimiento; pero ruego con Tulio en la acción de Gracias al Senado [...], que de no ser mi gratitud cabal, no se atienda el que soy nada; dígase que para no poder ser agradecido; hizo sobre mis fuerzas la obligación de serlo, lo multiplicado y grande de los beneficios... (Cladera, 1703, f. 8r.).

La aprobación del arcediano iba acompañada además de las censuras de dos respetados franciscanos novohispanos, José de Torres Pezellin y Agustín de Vetancurt. Probablemente conseguidos gracias a las influencias de Careaga en la Orden, ambos eclesiásticos servían como garantes criollos del vasco ante los ojos de la metrópoli. Si bien Suazo no pudo dejar de alu-

30 Inquisición. Vol. 725, exp. 1. AGN, México.

\section{()(1) $(3$}


dir una última vez a su procedencia académica ni tampoco dejar de mandar un dardo a sus detractores, su aprobación acompañada de los nombres de Vetancurt y Pezellin funcionó como la demostración pública de sus buenas intenciones. Sobre todo, esta última intervención del arcediano significó el éxito definitivo de Velázquez de la Cadena y su bando en imponer artificialmente el tema del patriotismo a la controversia.

A nivel del espacio público, esta aprobación constituyó el último episodio de la controversia, diez meses después de iniciada. Es probable que Suazo se resignara a redactarla ante la presión urbana. A nivel de su esfera profesional, la polémica llevó en cambio el arcediano a tratar de solucionar desde hacía unos meses ya el problema de su integración. A partir de finales del mes de julio, Suazo cambió en parte su actitud inicial para asumir una nueva estrategia, de orden participativa. Aunque mantuvo su discurso de ex colegial, lo equilibró con un desempeño nuevo en los asuntos de la arquidiócesis, destinado a demostrar su compromiso con sus pares. Cuando el 27 de julio el arzobispo Ortega y Montañés anunció a sus capitulares su intención de recaudar un nuevo impuesto para el Estado real, el subsidio eclesiástico (Aguirre, 2008, pp. 253-278), el nuevo arcediano asumió las reticencias colectivas del Cabildo encabezando sus tentativas de obstrucción. Además de quedar nombrado, el 3 de octubre, con cuatro capitulares más comisario de la décima o del subsidio, Suazo no dudó en enfrentarse solo, el 29 de octubre, con su prelado (Robles, 1972, t. III, pp. 288 y 294). Si bien finalmente el Cabildo no pudo resistirse a los mandamientos de Ortega y Montañés, el vasco se granjeó con su papel activo en la confrontación la legitimidad profesional que le faltaba y que no podía ganarse con la simple afirmación de una superioridad académica.

Ya que Suazo y Coscojales falleció pocos años después, el 24 de abril de 1708, está difícil determinar con base en su trayectoria posterior el impacto de los acontecimientos de 1703 sobre su carrera. ¿Consiguió el eclesiástico con su aprobación de noviembre apaciguar una opinión pública, mayoritariamente disgustada y extendida por la referencia patriótica? $\mathrm{O}$, al contrario, ¿quedó marcado por la impopularidad urbana? Sea como fuere, a nivel del espacio intelectual, el arcediano asumió, después y a pesar de la controversia, una sociabilidad heterogénea, pues nombró como albacea al dominico Antonio Pinto de Aguilar. ${ }^{31}$ Nacido en Castilla-y-León, el regular llegó muy

${ }^{31}$ Catálogo de defunciones de españoles, 1693-1714, f. 60r. AsM, México.

\section{()(1) $\$$}


joven a Nueva España, donde estudió y se ordenó para constituir un verdadero criollo de adopción. ${ }^{32}$

\section{CONCLUSIÓN}

Alto funcionario enviado por Madrid para ocupar uno de los primeros cargos del arzobispado, Suazo y Coscojales provocó en México una fase de efervescencia pública, alrededor de un sermón desafortunado que pronunció en el púlpito de la catedral, ante un auditorio amplio e informado. Un poderoso partido capitalino, liderado por el agustino Velázquez de la Cadena, se aprovechó rápidamente del episodio para tratar de volverlo en contra de otro adversario peligroso. Esta instrumentalización de la polémica se realizó sobre el argumento infundado de un patriotismo defensivo, comprensible para todos y que ampliaba el público urbano para varios meses.

Este texto no tiene la pretensión de haberlo dicho todo sobre los acontecimientos del año de 1703 y algunos aspectos importantes, como la cuestión de la opinión pública, han sido apenas aludidos aquí a pesar de su interés. Sin embargo, tal y como se presentan, la polémica y su desarrollo ofrecen a la reflexión dos elementos, metodológicos e historiográficos. Metodológicamente, el examen de las relaciones intelectuales y la atención prestada a los paratextos han proporcionado indicios valiosos y se trata pues de señalar su utilidad para la investigación. En términos historiográficos sobre todo, la controversia informa sobre una problemática amplia, el criollismo. Por una parte, y según aparece en las manos del clan de Velázquez de la Cadena, el patriotismo constituyó una poderosa arma política e intencional. Si Rubial García ha mostrado ya su instrumentalización parcial en el marco cerrado de la institución agustina, la originalidad de la polémica reside en la demostración de su manipulación en el contexto de un espacio urbano abierto, de parte de los miembros de una elite social y política. Artificialmente difundida desde la parte alta del espectro social, la acusación de antipatriotismo funcionó aquí para sus promotores, no como un grito de auténtica injusticia, sino como un resorte movilizador eficaz y maleable destinado a la población urbana. Por otra parte, el entorno relacional de los agustinos peninsulares señala la insuficiencia explicativa del antagonismo criollo-peninsular para

32 Indiferente, 220, N. 3. AGN, México.

\section{()(1) $(9$}


el espacio erudito y la existencia, paralela o inclusive preponderante, de las lógicas de alianzas o afinidades.

En ese sentido, este texto se inserta en un marco más amplio de análisis y estudios que señalan la pertinencia y el interés historiográfico de una relectura del llamado criollismo y sus manifestaciones (Entin, 2013; Escamilla, 2004; Pérez Vejo, 2010; Sato, 2014). En la línea de las interpretaciones decimonónicas, la historiografía sobre el tema ha visto mayoritariamente en el criollismo un fenómeno binario y altamente conflictivo. Además de presentarlo a menudo, en una lectura teleológica, como una señal anunciadora de las revoluciones independentistas, se ha tendido a atribuirle un papel primordial para entender las tensiones en las sociedades indianas (Brading, 1991; Céspedes del Castillo, 1983; Lafaye, 1985; Lavallé, 1993). Sin negar la realidad ni importancia del criollismo, se trata de matizar estas interpretaciones a favor de una comprensión más compleja. Por una parte, se trata de tomar en cuenta su alta plasticidad y la diversidad de sus variantes sociales, tanto sincrónica como diacrónicamente. Por otra, conviene reposicionarlo dentro del más amplio espectro de intereses y valores vigentes en el imperio hispánico, que pueden ser entre sí compatibles o rivales.

\section{LISTA DE REFERENCIAS}

Aguirre Salvador, R. (2003). El mérito y la estrategia: clérigos, juristas y médicos en Nueva España. México: UnAM.

Aguirre Salvador, R. (2008). El arzobispo de México Ortega Montañés y los inicios del subsidio eclesiástico en Hispanoamérica, 1699-1709. En F. Cervantes Bello y A. Tecuanhuey Sandoval, Poder civil y catolicismo en México, siglos XVI al XIX (pp. 253-278). México: UnAM.

Argüello M. (1711). Acción de gracias, a la Soberana Reyna del Cielo María SS. de Guadalupe en su magnífico templo, con que solemnizó el Real Acuerdo... México: Imp. Viuda Ribera.

Avendaño, P. (1699). Sermón de San Eligio, obispo de Noyons, que hizo D. Pedro de Avendaño Suarez de Soussa... México: Imp. Viuda Calderón.

Bertrand, M. (1999). Grandeur et misères de l'Office : les officiers de finances de Nouvelle-Espagne (XVIIe-XVIIIe siècles). París: PUs.

Brading, D. (1991). The first America: the spanish monarchy, creole patriots, and the liberal State, 1492-1867. Cambridge: Cambridge University Press.

\section{()(1) $(9$}


Carreño M. (1963). Efemérides de la Real y Pontificia Universidad de México según sus libros de claustros (T. I). México: UnAM.

Casado Arbonies, M. (2000). Proyección profesional desde las universidades de Sigüenza y Alcalá: una biografía colectiva de sus colegiales en América. En L. Enrique Rodríguez (coord.), Las universidades hispánicas: de la monarquía de los Austrias al centralismo liberal (t. 1, pp. 129-140). Salamanca: Universidad de Salamanca.

Céspedes del Castillo, G. (1983). América hispánica. Barcelona: Labor.

Cladera, G. (1703). Sermones de las santissimas imágenes de María señora nuestra de Aránzazu y Begoña, en su sumptuosa capilla, cita en el convento de Nuestro P. S. Francisco... México: Imp. Ribera Calderón.

Entin, G. (2013). El patriotismo americano en el siglo xVIII: ambigüedades de un discurso político hispánico. En V. Hébrard (ed.), Las independencias hispanoamericanas (pp. 19-34). Madrid: Casa Velázquez.

Escamilla, I. (2004). Razones de la lealtad, cláusulas de la fineza: poderes, conflictos y consensos en la oratoria sagrada novohispana ante la sucesión de Felipe V. En A. Mayer (ed.), Religión, poder y autoridad en la Nueva España (pp. 179-204). México: UNAM.

Escaray, A. (1681). Sermón panegyrico. Desagravios de Christo vida nuestra... México: Imp. Viuda Calderón.

Fernández de Manzilla (1703). Mystico complemento que en manos, piernas y pies se le dio a el templo de Religiosos Bethlemitas... México: Imp. Ribera Calderón.

González González, E. (2009). Del aula a la ciudad. Estudios sobre la universidad y la sociedad en el México virreinal. México: IIsUe.

Herrera, A. (2009). Los traspiés de un sermón famoso. En I. Arellano (comp.), Poesía satírica y burlesca en la Hispanoamérica colonial (pp. 191-206). México: Iberoamericana.

Huerta, M. T. (1997). Los Retes: prototipo del mercader de plata novohispano en la segunda mitad del siglo xVII. En A. Garritz (coord.), Los vascos en las regiones de México (pp. 71-86). Mexico: UnAM.

Kettering, S. (1986). Patrons, brokers, and clients in seventeenth-century France. Oxford: Oxford University Press.

Lafaye, J. (1985). Quetzalcóatl y Guadalupe: la formación de la conciencia nacional en México. México: FCE.

Laske, T. (2015). Savoir et pouvoir: trajectoires, postures et modes d'action des hommes d'Eglise en Nouvelle-Espagne (1680-1705). (Tesis de doctorado). Université de Toulouse, Toulouse, Francia.

Lavallé, B. (1993). Las promesas ambiguas: criollismo colonial en los Andes. Lima: PUCP.

\section{()(1) $(3$}


Lohman Villena, G. (1974). Los ministros de la Audiencia de Lima en el reinado de los Borbones 1700-1821: esquema de un estudio sobre un núcleo dirigente. Sevilla: Escuela de Estudios Hispano-Americanos.

López Quiroz, A. (1996). El P. Avendaño y la reyerta criolla. En A. Lara, A. Carlson (eds.), Retóricas verbales y no verbales (pp. 7-53). México: UNAM.

López Quiroz, A. (1998). Pedro de Avendaño. Fe de erratas: Ms. 95 de la Biblioteca del Museo Nacional de Antropología: edición, estudio introductorio, paleografía y notas. (Tesis de maestría). unam, México.

Millán de Poblete, J. (1696). Primacía de la Iglesia Santa, en opposicion de la Ingrata Synagoga delineada en la entrada de Christo Señor Nuestro... México: Imp. Viuda Lupercio.

Navarro, F. (1703). Voces del cielo repetidas en la tierra en obsequio de la Purissima Concepción de MARÍA SS Nuestra S... México: Imp. Ribera Calderón.

Pérez Vejo, T. (2010). Criollos contra peninsulares: la bella leyenda. Les Cahiers ALHIM, 19.

Robles, A. (1972). Diario de sucesos notables. México: Editorial Porrúa.

Rosenmuller, Ch. (2008). Patrons, partisans, and palace intrigues: the court society of colonial Mexico, 1702-1710. Algary: University of Calgary Press.

Rubial García, A. (1990). Una monarquía criolla: la provincia agustina de México en el siglo XVII. México: CNCA.

Ruiz Zavala, A. (1984). Historia de la provincia agustiniana del Santísimo nombre de Jesús de México (t. II). México: Porrúa.

Sanchiz, J. (1997). Lucas de Careaga, marqués de Santa Fe. La historia fugaz de un noble vasco en la Nueva España, una biografía en construcción. En A. Garritz (coord.), Los vascos en las regiones de México. Siglos XVI-XX (t. III, pp. 204-215). México: UNAM.

San Miguel, A. (1703). Fatiga y descanso de Christo en la conversión de la Samaritana. Idea de un príncipe político christiano... México: Imp. Ribera Calderón.

Sato, M. (2014). Revisando a criollos y al criollismo en el virreinato peruano del siglo XVII: el caso de Fray Buenaventura de Salinas y Córdoba. Historia y Cultura, 27, 83-117.

Silva Prada, N. (2007). La política de una rebelión. Los indígenas frente al tumulto de 1692 en la ciudad de México. México: Colmex.

Torres Puga, G. (2010). Opinión pública y censura en Nueva España: indicios de un silencio imposible, 1767-1794. México: Colmex.

Torremocha, M. (2012). Los estudiantes universitarios en la Edad Moderna: líneas de investigación. En L. Enrique Rodríguez, Historiografía y líneas de investigación en historia de las universidades: Europa mediterránea e Iberoamérica (pp. 219-242). Salamanca: Universidad de Salamanca.

\section{(ㅇ)(1) $(3$}


Zuazo y Coscojales D. (1703). Oracion evangelica y panegyrica de la purificación de María SSma... México: Imp. Guillena Carrascoso.

\section{OTRAS FUENTES}

Argüello, M. (1697). Sermón moral al Real Acuerdo de México al tiempo que tomó posession con pública entrada el Exmo Señor D. Joseph Sarmiento Vallardares, Conde de Moctezuma.... México: Imp. Guillena Carrascoso.

Arlegui, J. y Gálvez A. (1851). Crónica de la provincia de N.S.P.S. Francisco de Zacatecas. México: Ed. Cumplido.

Asúa y Campos, M. (1909). El valle de Ruiseñada: datos para su historia. Palencia: Imp. Gutiérrez.

Avendaño, P. (1998). Fe de erratas. En A. López Quiroz, Pedro de Avendaño. Fe de erratas. (Tesis de Maestría). unAm, México.

Beristaín de Souza, J. M. (1947). Biblioteca hispano americana septentrional (t. II). México: Ediciones Fuente Cultural. 